\title{
Application of System Clustering in Multi-node Distribution Center Location
}

\author{
Lingling $\mathrm{Li}^{*}$ \\ School of Management Engineering, Zhengzhou University, No.100 Science Avenue, Zhengzhou City, Henan \\ Province, China
}

Keywords: System clustering; Multi-node; Location; Deppon

\begin{abstract}
This paper is based on the study of domestic and foreign literature. First, a multi-node distribution center location model is established. And then it conducted a survey of Deppon logistics in Luoyang City. Taking Luoyang City Deppon Logistics as an example, this paper carries on the empirical analysis, and then verifies the applicability of the model.
\end{abstract}

\section{INTRODUCTION}

Since the 21st century, logistics management methods and the technology becoming more advanced, more and more people realize that logistics management has become an effective means in the market to obtain competitiveness and maintain competitive advantage. The development of a country's logistics status represents the country's comprehensive development and competitiveness in the same industry. Today's society, China's service industry has been completely open to the outside world. Many overseas logistics companies entered into the Chinese market, so the domestic logistics industry competition will gradually intensify. Logistics distribution center is a popular set of storage, sub, picking, secondary processing and other functions in an integrated warehouse.(Fei Wang,2006)The establishment of a modern logistics and distribution center is an important way for companies to strengthen the customer service system, save the cost of goods circulation process, and defeat other competitors in the industry. Distribution center is a vital part of the process of modern logistics distribution, it directly affects the supply chain of other costs, affects the user to receive the final cost of goods, and further affects the competitiveness of enterprises in the logistics. Therefore, a reasonable and efficient distribution center will greatly improve the efficiency of the supply chain and user's satisfaction. The distribution center is a bridge between the supply chain front end suppliers and the end customers. It uses modern information technology and operation methods to carry out value-added services such as storage, transportation and further processing of goods to realize the value of the goods in circulation. At the same time,it use advanced management methods to manage so as to enhance the efficiency of the entire supply chain.The role of the distribution center in the logistics system is to improve the overall speed of the logistics system. The distribution center's geographical advantages can optimize the supply chain structure. Distribution center can replace the traditional dealers and the middle of the wholesalers. Distribution center swept the whole of the transport and storage, simplifying the flow of goods, making the entire supply chain cost lower. To a large extent,it also improves the efficiency of the supply chain. In addition, the rational distribution center can reduce the supply chain bullwhip effect. In the process of circulation of goods, it not only reduces the distributors and intermediate wholesalers but also delivered goods from the distribution center directly. Even if the demand for the following retailers changes, but when all the changes are concentrated in the distribution center. According to the probability of statistical knowledge I can know, the distribution center aggregate demand changes will be much smaller than the downstream customer demand changes in the sum. The distribution center is uniquely positioned to minimize the cost of the supply chain and to improve the level of supply chain services. But to truly realize the efficiency of logistics and distribution center, according to the needs of customers to establish transport cargo system,to ensure the standardization of distribution process, and save business logistics costs, then the distribution center location problem is worth us to research.

Based on the study of domestic and foreign literature, this paper mainly discusses the location problem of multi - node distribution center by using system clustering method. First construct a class, how many samples there are how many types, each category contains only one sample. Secondly, according to the calculation formula of various distance in cluster analysis, the distance to be used is selected, and the survey data is substituted into the calculation formula. The distance between the samples is calculated, and the two of the nearest samples are merged into one.Finally, calculate the distance between the newly merged class and the existing class, and then merge the two distances from the shortest, and so on. After the SPSS analysis, when the number of classes is merged into one, you can get the clustering graph, then I can determine the number of categories and the number of classes. (Yunzong Xie ,2017)

\section{ESTABLISHMENT OF MULTI- NODE DISTRIBUTION CENTER LOCATION MODEL}

The location problem of the distribution center is critical to the decision-making of the company management. The appropriate distribution center can save the logistics cost, improve the distribution efficiency and the customer's satisfaction. I can use the system cluster analysis method to determine the need to establish the number of distribution centers in a good 
area to find the best distribution center location. The establishment of the model is to meet the needs of enterprises and customers and then to find out making the lowest total cost of location of the new distribution center.(Jili Sun,2010)

\subsection{Assumptions of the Model}

(1) The market demand is known and the demand for each sample are gathered at a certain point, on behalf of the total demand for this sample too easy to solve the model.

(2) I only consider the static location of the site, ignoring the future of income and cost changes

(3) Here I assume that the transportation costs are proportional to the distance, that is, the transportation rate is linear

(4) I do not consider the difference in costs due to different vehicles, assuming that all transport vehicles are the same.

(5) I do not consider the difference in fixed management costs due to the different location of the distribution center, including plant construction, staff salaries, and the inventory costs of the goods

\subsection{Description of the Relevant Costs in the Model}

The purpose of our model is to meet the needs of the market, taking into account the various costs of the distribution center, including fixed management costs, vehicle maintenance costs, distribution center to downstream customers delivery costs, and then rational allocation and using of various resources to make the sum of these costs the smallest. The cost in the model can generally be divided into fixed and variable costs. The fixed costs of the distribution center mainly include the construction costs of fixed assets facilities such as plant and equipment, personnel wages. Variable costs, including the cost of goods as Ill as loading and unloading charges. Transportation costs also have two parts, one is the vehicle maintenance costs, and the other is the driver's wages. In order to facilitate the calculation, I put the driver's wages into the distribution center fixedrate staff wages and assume that each distribution center vehicle maintenance costs are the same. The fuel consumption during the distribution process is not sure, the distance and the number of goods will affect the fuel costs. In the model, I ignore the impact of the road conditions and the number of vehicles loaded on the fuel combustion rate, that is the unit mileage of the transport costs are the same.

\subsection{Establishment of Site Selection Model}

\subsubsection{The Description Involved in the Relevant Symbol in the Model}

D: the number of distribution centers

$\mathrm{C}$ : the number of downstream customers

$\mathrm{T}$ : total number of transport vehicles

${ }^{\operatorname{Max}} C_{t}$ : The maximum load of vehicle $t$

$\operatorname{Max}_{i}$ : Customer c needs the number of delivery per month

${ }_{D I S} T_{c i}$ : Customer c to the distribution center i distance, according to the actual distance to determine, different customers have different distances $f$ : Distribution center to the customer's transportation rate

$T_{c}$ : Customer c needs the number of delivery per month

$Q_{c}$ : The total amount needs of customer c

$V_{c}$ : the delivery quantity from distribution center to customer c each time

$D_{i}$ : The fixed management fee for distribution center i

$M C_{i}$ : Maintenance costs for a single transport vehicle at the distribution center $\mathrm{i}$

$V C_{i}$ : The variable costs of the unit goods at the distribution center $\mathrm{i}$ (including the discharge and inventory costs, etc.)

The decision variables included in the model are:

$C U S_{c i}=\left(\begin{array}{l}1, \text { Customer } \mathrm{c} \text { is delivered by vehicle of distribution center } \mathrm{i} \\ 0, \text { Customer } \mathrm{c} \text { is not delivered by vehicle of distribution center } \mathrm{i}\end{array}\right.$

$D T_{i}$ : The total number of transport vehicles assigned to distribution center $\mathrm{i}$

$$
\begin{aligned}
& \operatorname{MinTC}=\sum_{i=1}^{D} D_{i}^{*} D C_{i}+\sum_{i=1}^{D} M C_{i}^{*} D T_{i}+\sum_{i=1}^{D} \sum_{c=1}^{C} f * V_{c} * D I S T_{c i} \\
& +\sum_{i=1}^{D} V C_{i} \sum_{c=1}^{C} T_{c} * C U S_{c i}
\end{aligned}
$$

\subsubsection{The Establishment Of The Site Model}

Based on the above assumptions, I derive the objective function as:

$\operatorname{DIST}_{c i}=\sqrt{\left(X-x_{C}\right)^{2}+\left(Y-y_{c}\right)^{2}}$

among them:

Restrictions:

$D T_{i} \leq T * D C_{i}, i=1,2 \ldots \ldots I$

$\sum_{i=1}^{I} C U S_{c i}=1, c=1,2 \ldots \ldots . C$

$\sum_{c=1}^{c} V_{c} * C U S_{c i} \leq \operatorname{Max}_{i} * D C_{i}, i=1,2 \ldots \ldots I$

$\sum_{c=1}^{c} C U S_{c i} * V_{c} \leq \operatorname{Max} D_{i}, i=1,2 \ldots \ldots . I$

$D C_{i}=0,1$ for all $\mathrm{i}$

CUS $_{c i}=0,1$ for all c,i

$D T_{i}$ is an integer, for all $\mathrm{i}$

The objective function is shown above.The first item in the objective function indicates that the fixed management fee for the new distribution center includes plant construction and equipment investment.The second item shows the maintenance of the distribution center vehicle.The third term represents the sum of the delivery costs of the distribution center to the customer for one month.The fourth term represents the variable costs of the distribution center, such as inventory costs and handling charges.

In the constraint, the first constraint indicates that the number of vehicles assigned to the distribution center must be less than the total number of vehicles.The second constraint indicates that each customer will have a distribution center for their delivery.The third constraint indicates that the goods delivered by the distribution center must be less than or equal to all the goods in the distribution center.The fourth constraint indicates that the storage volume of the distribution center must be greater than the amount of goods to be 
delivered.

\section{ANALYSIS OF MULTI - NODE DISTRIBUTION CENTER-A CASE STUDY OF DEPPON LOGISTICS IN LUOYANG CITY}

I found 10 Deppon logistics business on the map in Luoyang City. On the map, I take the Wangcheng Zoo as the origin, with the north-south direction for the y-axis and the north is positive, east-west direction for the $\mathrm{x}$ axis, and east for the positive, in kilometers. I find out the coordinates of the 10 business outlets: $\mathrm{A}(4.1,-$ 3), $\mathrm{B}(3.6,1.9), \mathrm{C}(0, \quad 3.7), \mathrm{D}(-1.7, \quad-5.7), \mathrm{E}(3.5,1.8), \mathrm{F}(-$ 3.2,0.3), G(-0.4,1.5),H(-4.1, -6.1),I(3.9, -5),J(-1.3, -3).I use Square Euclid distance to calculate Sample Distance Matrix. Now I put these coordinates into the SPSS software, the system cluster analysis of these 10 samples for cluster analysis. I can get the tables shown in below:

Table 1 Approximate Matrix

\begin{tabular}{|c|c|c|c|c|c|c|c|c|c|c|}
\hline \multicolumn{11}{|c|}{ Approximate Matrix } \\
\hline \multirow{2}{*}{ sample } & \multicolumn{10}{|c|}{ Square Eudidean Distance } \\
\hline & $1 \mathrm{~A}$ & $2 \mathrm{~B}$ & $3 \mathrm{C}$ & 4D & $5 \mathrm{E}$ & $6 \mathrm{~F}$ & $7 \mathrm{G}$ & $8 \mathrm{H}$ & $9 \mathrm{~J}$ & $10 \mathrm{~K}$ \\
\hline $1 \mathrm{~A}$ & 0.000 & 1.871 & 3.188 & 4.037 & 1.808 & 6.345 & 3.649 & 7.688 & 0.312 & 3.014 \\
\hline $2 \mathrm{~B}$ & 1.871 & 0.000 & 1.588 & 7343 & 0.002 & 4.976 & 1.666 & 11.047 & 3.669 & 4.327 \\
\hline $3 \mathrm{C}$ & 5.188 & 1.588 & 0.000 & 7.091 & 1.544 & 1.947 & 0.389 & 9.120 & 7.390 & 3.625 \\
\hline 4D & 4.037 & 7.343 & 7.091 & 0.000 & 7.118 & 3.000 & 4.159 & 0.608 & 3.279 & 0.577 \\
\hline SE & 1.808 & 0.002 & 1.544 & 7.118 & 0.000 & 4.812 & 1.579 & 10.767 & 3.517 & 4.152 \\
\hline $6 \mathrm{~F}$ & 6.345 & 4976 & 1.947 & 3.000 & 4.812 & 0.000 & 0.921 & 3.232 & 7369 & 1.210 \\
\hline $7 \mathrm{G}$ & 3.649 & 1.666 & 0.389 & 4.159 & 1.579 & 0.912 & 0.000 & 5.855 & 5.159 & 1.640 \\
\hline $8 \mathrm{H}$ & 7.688 & 11.047 & 9.120 & 0.608 & 10.767 & 3.232 & 5.855 & 0.000 & 6.707 & 1.549 \\
\hline 9I & 0.312 & 3.669 & 7.390 & 3.279 & 3.571 & 7.369 & 5.159 & 6.707 & 0.000 & 3.102 \\
\hline $10 \mathrm{~J}$ & 3,014 & 4.327 & 3.625 & 0.577 & 4.152 & 1.210 & 1.640 & 1.549 & 3.102 & 0.000 \\
\hline
\end{tabular}

Table 2 Clustering chart

\begin{tabular}{|c|c|c|c|c|c|c|}
\hline \multicolumn{7}{|c|}{ Clustering chart } \\
\hline \multirow[t]{2}{*}{ Order } & \multicolumn{2}{|c|}{ Cluster combinaticn } & \multirow[t]{2}{*}{ coefficient } & \multicolumn{2}{|c|}{$\begin{array}{l}\text { The first occurence of a } \\
\text { cluster }\end{array}$} & \multirow[t]{2}{*}{ Thenert order } \\
\hline & Cluser 1 & Cluster 2 & & Cluster 1 & Cluster 2 & \\
\hline 1 & 2 & 5 & 0.002 & 0 & 0 & 8 \\
\hline 2 & 1 & 9 & 0.312 & 0 & 0 & 9 \\
\hline 3 & 3 & 7 & 0.389 & 0 & 0 & 6 \\
\hline 4 & 4 & 10 & 0.577 & 0 & 0 & 5 \\
\hline 5 & 4 & 8 & 0.608 & 4 & 0 & 7 \\
\hline 6 & 3 & 6 & 0.912 & 3 & 0 & 7 \\
\hline 7 & 3 & 4 & 1.210 & 6 & 5 & 8 \\
\hline 8 & 2 & 3 & 1.544 & 1 & 7 & 9 \\
\hline 9 & 1 & 2 & 1.808 & 2 & 8 & 0 \\
\hline
\end{tabular}

Table 3 Cluster members

\begin{tabular}{r|r|r|r|r|r|}
\hline \multicolumn{7}{|c|}{ Cluster members } \\
\hline \multicolumn{7}{|c|}{ Sample } & \multicolumn{7}{|c|}{ Cluster 6 } & Cluster 5 & Cluster 4 & Cluster 3 & Cluster 2 \\
\hline 1A & 1 & 1 & 1 & 1 & 1 \\
\hline 2B & 2 & 2 & 2 & 2 & 2 \\
\hline 3C & 3 & 3 & 3 & 3 & 2 \\
\hline 4D & 4 & 4 & 4 & 3 & 2 \\
\hline 5E & 2 & 2 & 2 & 2 & 2 \\
\hline 6F & 5 & 5 & 3 & 3 & 2 \\
\hline 7G & 3 & 3 & 3 & 3 & 2 \\
\hline 8H & 6 & 4 & 4 & 3 & 2 \\
\hline 9I & 1 & 1 & 1 & 1 & 1 \\
\hline 10J & 4 & 4 & 4 & 3 & 2 \\
\hline
\end{tabular}

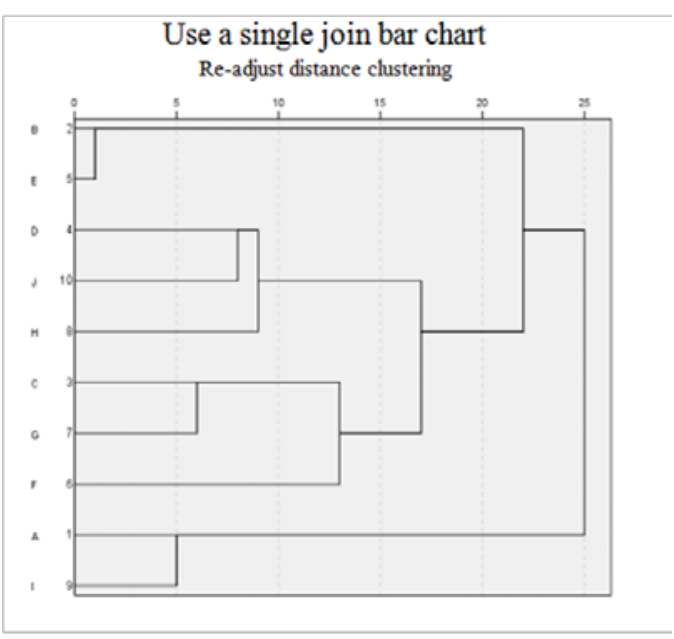

Figure 1 Use a single join bar chart

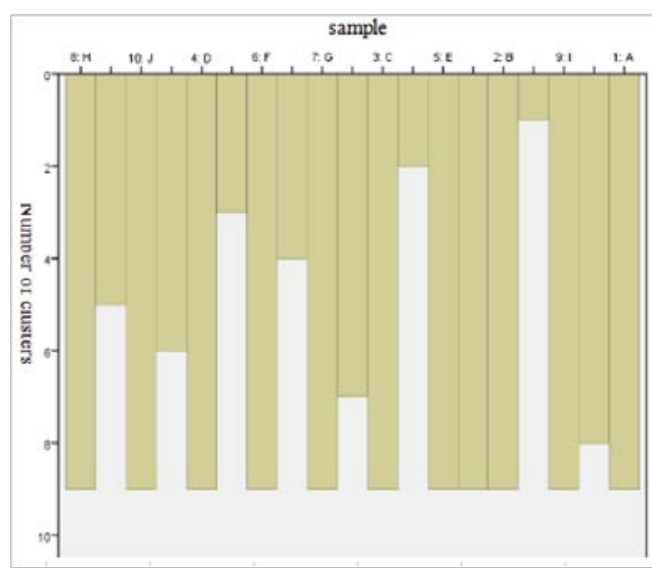

Figure 2 sample

According to the clustering analysis of the single join method of cluster analysis in SPSS software, it is better to divide these 10 business outlets into four categories. A, I for the first category; C, G, F for the second category; $\mathrm{D}, \mathrm{J}, \mathrm{H}$ for the third category; B, E for the fourth category. According to the survey, Luoyang City District 1 square meters of rent is about 8 yuan per month. Each distribution center determines the area of the distribution center based on how much downstream demand. Each distribution center requires at least one administrator,The administrator is responsible for receiving the goods and arrange delivery, whose salary is about 4,000 yuan a month.According to the survey, each vehicle mileage of $8000 \mathrm{~km}$ need to be maintained once, each maintenance costs about 300 yuan.Here I assume that each car is maintained once a quarter.Now 1 liter oil is 4.8 yuan, 1 $\mathrm{km}$ oil costs 0.8 yuan.Each car needs a driver, some vehicles may also need a loader.The driver 's salary is about 3,500 yuan every month, a loader's wages is about 2,500 yuan a month.So I need to know every Deppon's logistics point's cargo flow.the cargo flow is as the demand for this network.According to the needs of each network,I arrange the number of vehicles for every distribution center.Here I take the third type as an example to verify the correctness of the model.J point of the daily cargo flow is about $8760 \mathrm{~kg}$.D point of the daily cargo flow is about $3200 \mathrm{~kg} . \mathrm{H}$ point of the daily cargo flow is about 6400kg.Here in order to facilitate the calculation, I unified provisions of the transport vehicles 
are 4.2 meters long small trucks. each vehicle can load 10 tons of goods.Distribution center requires two vehicles and $1 \mathrm{~kg}$ of goods transported $1 \mathrm{~km}$ is 1.8 yuan.I will be the driver's wages included in the distribution center staff wages, which is attributed to fixed management costs.I put these cost data into the model:

$$
\operatorname{minTC}=4000+3500 * 2+100 * 2+\sum_{i=1}^{3} 30 * f * V_{i} * \sqrt{\left(x-x_{i}\right)^{2}+\left(y-y_{i}\right)^{2}}+100 * 2 * 30
$$

F takes a fixed value of 1.8, $V_{i}$ represents the distribution of each network of goods.Input the objective function and data to lingo8.0 .The results are Figure 3, Figure 4 as follows:

$\begin{array}{|rcc|}\text { Variable } & \text { Value } & \text { Reduced Cost } \\ \text { X } & -1.3000001 & 8565.819 \\ \text { X1 } & -1.300000 & 0.000000 \\ Y & -3.0000001 & 14246.84 \\ \text { Y1 } & -3.000000 & 0.000000 \\ \text { X2 } & -1.700000 & 0.000000 \\ \text { Y2 } & -5.700000 & 0.0000000 \\ \text { X3 } & -4.100000 & 0.000000 \\ \text { Y3 } & -6.1000000 & 0.0000000 \\ \text { Row } & \text { Slack or Surplus } & \text { Dual Price } \\ 1 & 0.000000 & -1.000000 \\ 2 & 0.000000 & -0.3324321 \mathrm{E}+09 \\ 3 & 0.0000000 & -0.3324327 \mathrm{E}+09 \\ 4 & 0.000000 & -0.3319591 \mathrm{E}+09 \\ 5 & 0.0000000 & -0.3319543 \mathrm{E}+09 \\ 6 & 0.000000 & -0.3319523 \mathrm{E}+09 \\ 7 & 0.0000000 & -0.3319514 \mathrm{E}+09 \\ & & \\ & & \end{array}$

Figure 3 Output result

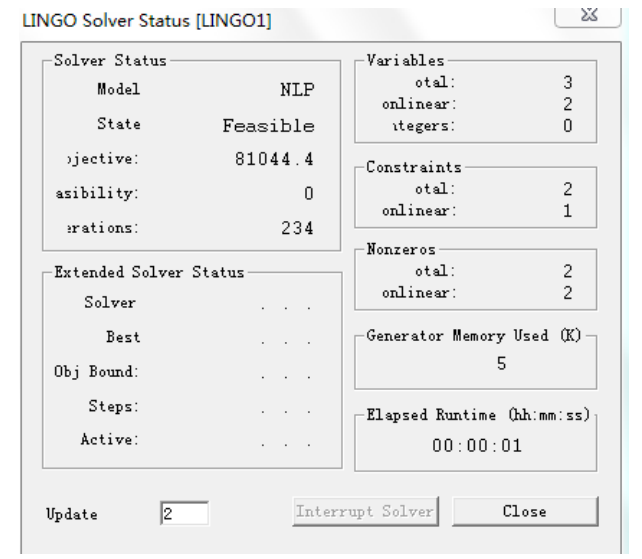

Figure 4 LINGO solver status
According to the calculated results of lingo8.0, D, J, $\mathrm{H}$ the three samples aggregation classes need to create a new distribution center. The coordinates of the distribution center are $(-1.300001,-3.00001)$. The cost of this distribution center is about 8,1044 yuan per month. Similarly, I can bring the other three types of data into the model, using lingo8.0 to calculate.and finally the cost of the four distribution centers together is the 10 districts' total cost of the new distribution center.

The new coordinate position is compared with the coordinates of the original network.Obviously I can find that the location of the new distribution center is very close to the cargo flow.

\section{CONCLUSIONS}

In this paper, the method of system cluster analysis is used to explore the location problem of multi - node distribution center. First of all, I give a brief introduction to the development of China's logistics industry status quo. I have a simple investigation of Luoyang City Deppon logistics, and then use the system cluster with SPSS software to cluster analysis of nodes. Finally, I input the data into the model, using lingo8.0 to calculate to find the best location of the distribution center.

\section{REFERENCES}

[1] Fei Wang, Yu Xu, 2006. Research on Location of Logistics Distribution Center [J]. Logistics Technology, (06): 35-37.

[2] Zongyun Xie, Xiaohui Zhu, 2017. Analysis on Investment and Financing of Tourism in Yunnan Provinces - Based on SPSS Cluster Analysis [J] .Chinese Market, (18): 327-328.

[3] JiLi Kong, ZhuGu, XinSun, AiLan Feng,2010. Study on Site Selection of Multi-Node Distribution Center Based on System Clustering and Gravity Method [J]. Logistics Technology, 29 (05): 83-85. 